\title{
Establishing the IT Student's Perspective to e-Learning: Preliminary Findings from a Queensland University of Technology Case Study
}

\author{
Helen Partridge and Sylvia Edwards \\ Queensland University of Technology, Brisbane, Australia
}

\author{
h.partridge@qut.edu.au s.edwards@qut.edu.au
}

\begin{abstract}
The Queensland University of Technology (QUT) is committed to providing outstanding learning environments and programs that lead to excellent outcomes for students. This paper will discuss how the Faculty of Information Technology is helping to meet this commitment by using information and communication technology to transform teaching and learning in ways in which engage and challenge students. The paper will provide a case study explore how e-learning is being implemented within the Bachelor of Information Technology. The paper will discuss the practical implications of incorporating e-learning into the teaching curriculum and how it impacts on the teaching and learning process. Student attitudes and expectations towards e-learning will be explored. The paper concludes that e-learning should be a part of a 'whole of learning' approach in which technology is not just an add on to traditional teaching, nor is it the central focus of teaching, but rather, it is one of many tools that is integrated into the curriculum to foster learning. The current project suggests that students appreciate and prefer a mix of e-learning and face-to-face classes and that e-learning is most successful when a holistic approach to teaching and learning is taken.
\end{abstract}

Keywords: e-learning, online learning and teaching; online searching, IT education, information literacy, student attitudes and expectations, holistic teaching and learning.

\section{Introduction}

E-learning has become an integral part of the teaching and learning process in higher education. The Australian Universities Teaching Committee (2002) suggested that despite its short history, "e-learning is experiencing a rapid penetration as education and training institutions at all levels of business and government, both nationally and internationally seek to capitalize on its promise of increasing access to learning opportunities as well as enhancing the quality of learning outcomes" (p. 2). In 2002 the Australian Department of Education Science and Training (DEST) released findings from a nation wide exploration into online education within 40 of the 43 Australian universities. With $54 \%$ of all units offered in higher education containing an "online component" DEST concluded that "Australian universities have made significant investments in online

Material published as part of this journal, either on-line or in print, is copyrighted by Informing Science. Permission to make digital or paper copy of part or all of these works for personal or classroom use is granted without fee provided that the copies are not made or distributed for profit or commercial advantage AND that copies 1) bear this notice in full and 2) give the full citation on the first page. It is permissible to abstract these works so long as credit is given. To copy in all other cases or to republish or to post on a server or to redistribute to lists requires specific permission from the publisher at Publisher@InformingScience.org education, both in terms of the development of courses and support services and the infrastructure necessary to deliver them" (Bell, Bush, Nicholson, O'Brien, \& Tran, 2002, p. 2). The benefits of e-learning, and consequently the driving forces behind the e-learning uptake in higher education, 
have been widely discussed. They include greater accessibility and flexibility, a more cost effective and cost efficient program of study, and a higher quality student learning experience.

In 2004 the Queensland University of Technology (QUT) stated that one of its' four ambitions was to "provide outstanding learning environments and programs that lead to excellent outcomes for graduates" (QUT, 2003, p. ii). QUT challenges its academic staff to meet this ambition by making "a coordinated and strategic effort to use increasing capacity and flexibility of...[information and communication] technologies to transform our teaching and learning in ways which engage and challenge students" (QUT, 2003, p. 4).

Keller and Cernerud (2002) suggest that the current discussion on the use of information and communication technology in learning, or what is now more commonly known as e-learning, has primarily focused on ways in which the teacher incorporates new technology into their teaching. They suggest that whilst there are "reports of students overwhelming preferring to take class using e-learning than a traditional course" $(2002$, p. 56) very few studies explore e-learning from the students point of view. Since Keller and Cernerud's comments were published, however, several studies have been published exploring student perceptions and expectations regarding elearning (Small \& Lohrasbi, 2003; Wang, 2004). This paper will add to the growing body of literature exploring students attitudes towards e-learning through a discussion of how e-learning is being implemented and viewed by students within the Faculty of Information Technology at QUT.

\section{E-Learning}

\section{A Definition}

Professor Stephen Heppell, Director of Ultralab, the Anglia Polytechnick University's learning technology research centre provides the following informal definition of e-learning:

“it isn't delivering knowledge, it isn't building 'teaching machines', it isn't edutainment, it isn't doing what we did before but cheaper. But it is the opportunity for [students] to explore new expertise, take new risks, develop new collaborations, gain new understanding...It is about creativity not productivity....It is about multiple media and multiple learning styles together with the opportunity to change the mix to suit the context, the learners, their predispositions and their entitlements....It is also about allowing teachers to do what they entered the profession to do: inspire, lead and delight [students] whilst rejoicing in their rapid progression" (2002, para. 5)

More formally, e-learning has been defined by the American Society for Training and Development as "anything delivered, enabled, or mediated by electronic technology for the explicit purpose of learning" (Hicks, n.d., para. 1). Or more recently as "instruction and learning experiences that are delivered via electronic technology such as the Internet, audio, videotape, satellite broadcast, interactive TV, and CD-ROM" (Imel, 2002, p. 3). Jackson (2001 cited in Parker, 2003) provides a more detailed perspective of e-learning by proposing that e-learning can be further subdivided into "technology-delivered e-learning" and "technology enhanced e-learning". Technologydelivered e-learning is where the learner is "never in physical close proximity to the instructor and may be delivered via a blend of asynchronous and synchronous technologies" (p. 316). Technology enhanced e-learning is where the learner "has the opportunity to meet face-to-face with the instructor is a supplement to traditional, on-campus learning" (p. 316). It is this latter view of e-learning which will be explored in the current paper. 


\section{E-Learning at the Queensland University of Technology}

QUT is a member of the Australian Technology Network (ATN), which is a consortium of technology and industry focused institutions, including Curtin University, RMIT University, University of South Australia and the University of Technology Sydney. In 2003 QUT had approximately 40,000 students enrolled in eight faculties: Built Environment and Engineering, Education, Business, Information Technology, Health, Science, Law and Creative Industries.

QUT is committed to "[providing] outstanding learning environments and programs that lead to excellent outcomes for graduates" (QUT, 2003, p. ii). In pursuit of this goal the university has identified as one of its "top priorities" the "[integration of information and communications technology into our teaching...functions and infrastructure" (QUT, 2003, p.ii). To fulfill this top priority the university has developed an Online Teaching (OLT) environment to foster the development of e-learning or online learning approaches within the university, and the academic staff are encouraged to use the OLT "in conducting and facilitating instruction" (QUT, 1999, p. 2).

As the ATN is committed to ensuring both the strategies for, and the successful use of, e-learning within its member institutions, in 2004 the ATN Teaching and Learning Committee (TALC) proposed an "evaluation of e-learning across the ATN universities". The evaluation was aimed to assist the ATN universities by developing an enhanced understanding of (i) the consequences of the range of online learning strategies used across the ATN for staff and students; (ii) the student experiences and expectations of a range of uses of online teaching; and (iii) the support needs of academics, including technical, administrative and pedagogical issues. The current paper will support this evaluation by providing preliminary findings in regards to the student experiences and expectations.

\section{The Case Study}

\section{The Bachelor of Information Technology}

The Bachelor of Information Technology (BIT) is the primary course offered within the QUT Faculty of Information Technology. The course is completed in three years full time or six years part time. All students complete a common first year of 8 introductory units. From this base, students choose a major, comprising 12 units of study, in areas such as data communications, information systems, software engineering, electronic commerce, or emerging technologies. Students are then free to choose 4 units of electives for within the IT faculty or from one of QUT's other seven faculties. The BIT is aimed at providing students with the theoretical skills and practical knowledge required to become successful practitioners in the ever-changing IT industry. Graduates from the BIT can enter a diverse range of careers including systems programmer, computer scientist, systems analyst, information manager, games developer, multimedia specialist, data base manager and web developer. In 2003 there were 2725 students enrolled in the BIT course.

\section{ITB322 Information Resources}

ITB322 Information Resources is an elective unit offered within the QUT Faculty of Information Technology. The unit introduces students to the value of information both personally and professionally by encouraging them to explore the wide variety of information resources available, independent of the resources format. There is a major focus on the identification of user needs and the development of information searching skills across a wide variety of online resources, including bibliographic databases, the Internet and traditional print materials such as grey literature books, journals and conference proceedings. The unit can be taken by any undergraduate enrolled at QUT, and has an average enrolment of 46 students per semester. In Semester 2200352 stu- 
dents were enrolled in the unit, 10 part time and 42 full time. Twelve students were classified as International enrolments.

\section{E-learning in ITB322}

Roberts and Jones (2000) identified four models of e-learning: the naïve model; the standard model; the evolutionary model; and, the radical model.

1. The naïve model is the most widely used. It may be characterised as "putting the lecture notes on the Web". It provides no opportunity for interaction or feedback. Although widely disparaged in the literature this model has two major advantages. Firstly, it is relatively cheap to implement, in terms of both hardware and software resources and staff time. Secondly, the model is less threatening to students, as no or little advanced technology skills are required.

2. The standard model attempts to utilise the advantages of the technology to allow a significant degree of communication and interaction between students and staff. Features of the standard model include a subject home page that provides access to both subject materials (i.e. unit outlines, assessment guide) and session materials (i.e. lecture notes, tutorial activities, reading materials) as well as the provision of email lists and newsgroups to open up communication between students and with students and the subject coordinator. The major disadvantages to the standard model of e-learning is the increased amount of time required to establish, maintain and keep current throughout the semester, and the increased expectations of students that all online information is to be error free and up-todate at all times.

3. The evolutionary model allows the exact method of course delivery to 'evolve' from semester to semester based on identified strengths and weaknesses and weekly anonymous feedback from students. Aspects which normally distinguish the evolutionary model from the standard model include lectures are pre-recorded and available both on CD and from the web; animations are used to explain many of the concepts; 'live' lectures are given only in response to students requests for further explanation of particular topics; assignments are submitted, recorded, marked and returned electronically; a feedback mechanism is provided for students to give constructive comment on how the subject is progressing.

4. The radical model dispenses with the traditional lecture format entirely instead and students are formed into groups to learn by interacting amongst themselves by using the vast amount of existing web-based resources, with the academic staff member providing guidance as and when required.

Based upon these four models the application of e-learning in the unit ITB322 can best be described as siting between a standard and an evolutionary model. A brief description of e-learning within the unit will follow. 
Students enrolled in ITB322 are required to attend three hours of classes (lectures and computer based practicals) per week for 13 weeks. The framework by Oliver (1999) and later modified by Luca, Oliver, Omari and Dunbar (2001) for embedding e-learning within a unit's curriculum guided the e-learning development within the ITB322. According to Luca et al., successful instructional design involving online learning should consist of a finely developed relationship between assessment, learning activities, learning supports and learning resources (Figure 1). In this relationship assessment is "instrumental to the whole design process and is considered in each element of the framework" (Luca, Oliver, Omari \& Dunbar, 2001, p. 11-1). Oliver argues that considering all four elements in the instructional design process will "highlight the importance of planning specific roles for learners, the teacher and the technology in the learning environment".

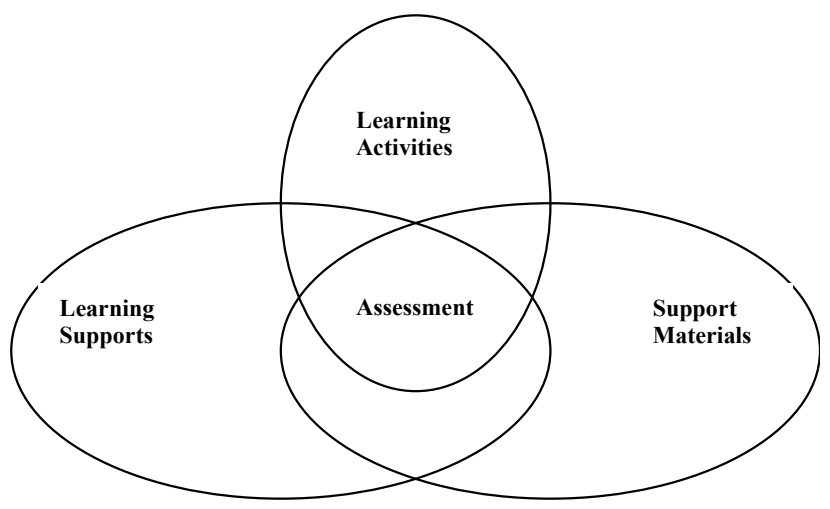

Figure 1 The framework developed by Oliver (Luca, Oliver, Omari, Dunbar 2001)

In ITB322 three assessment items are used. Table 1 provides a brief description of each item. The three assignments provide the students the opportunity to reflect upon, develop and practice their information searching skills. The assignments are designed to provide authentic learning experiences based upon 'real life' practices of industry professionals. All learning activities, learning supports, and learning resources are designed to support the assessment. All three assignments are submitted in hard copy via the student resource centre, however assignment 3 - the reflective learning journal - also requires the students to submit their fortnightly journal entries electronically via the Online Assignment System (OAS). The journal is marked by the unit teaching staff and returned to the student by loading the marked file on the OAS. A link to the OAS is provided on the unit's online teaching or OLT site.

Learning activities in ITB322 are designed to "promote authentic context, self regulation and reflection" (Luca, Oliver, Omari \& Dunbar, 2001, p. 11-2). A constructivist view of teaching and learning guides the design of the unit learning activities. According to a constructivist view of learning an individual learns by constructing, interpreting and modifying their representations of reality based upon their own experiences. In particular, as an individual we learn by being part of a community of learners in which they can collaboratively learn, explore, test and hypothesise (Aldrerman \& Milne, 1999). As such learning activities in ITB322 are collaborative in nature and provide the opportunity for students to support each other through the learning processes. Small group work, self assessment, and class discussion are key ingredients in this unit. The unit's teaching team provides support during learning activities by fostering a safe and non-threatening learning environment, guiding the students through the learning process with regular constructive comment and feedback. 
Table 1: ITB322 Assessment Items Semester 22003

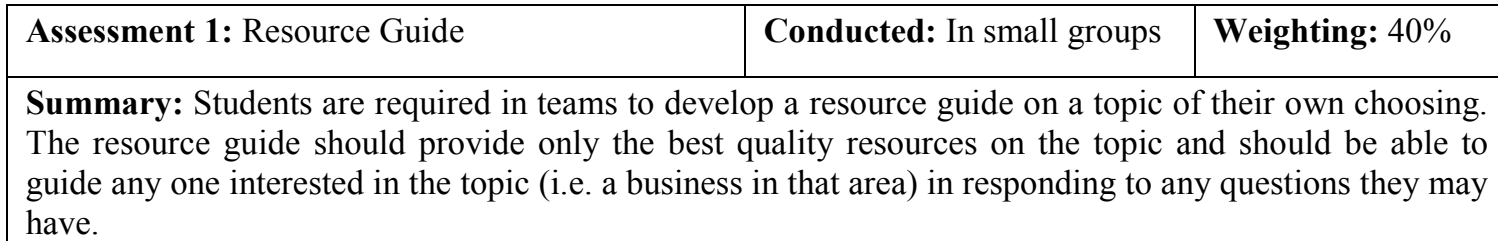

Submission Method: In hard copy via the student resources room

Assessment 2: Information Consultant's Report
Summary: Students are asked to pretend they have recently been appointed as an Information Consult-
ant for a large information service. They have been approached by their first client and are required to
meet their specific information need (i.e. they are to select from 3 possible scenarios). To meet this need
students are required to design and conduct searches of online resources (i.e. bibliographic databases or
Internet search tools) that will produce high quality results.

Submission Method: In hard copy via the student resources room

\begin{tabular}{|l|l|l|}
\hline Assessment 2: Reflective Learning Journal & Conducted: Individually & Weighting: $20 \%$ \\
\hline
\end{tabular}

Summary: Each student is required to write and submit six journal entries over the course of the semester. Entries are submitted fortnightly. Students are asked to write their critical and reflective thoughts on what they are doing, seeing, reading, hearing and learning.

Submission Method: Entries 1-5 electronically via the Online Assignment System (OAS) the full journal (i.e. entries 1-6) in hard copy via the student resources room

The unit's OLT site was established to act as the key support material in the unit and as a consequence, it has taken on the role as the primary face of e-learning within the unit. The main page of the OLT site is provided in Figure 2.

Key features of the site include:

- Access to all materials used in the learning activities as well as recommended readings and links to useful resources on key topics, such as teamwork and online searching.

- Access to general unit information, including the unit outline and the assessment guide.

- An online discussion forum through which students could communicate freely with others in the unit without the restrictions of time and distance.

- A Student Recommendations Page where student's can contribute to the learning community by adding the details of any interesting or relevant materials they have found during the course of the semester.

- A "Have a Say" page providing the opportunity for students to submit constructive comments and feedback on the unit via the Web On-Line Feedback (WOLF) system. All comments submitted are confidential and anonymous.

- A unit email list to facilitate communication between unit co-ordinator and students. All of the messages sent throughout the semester are placed in a Notices archive on the page.

In addition, the site provides a link to the Online Assignment System (OAS) that was developed in house in the Faculty of Information Technology to allow electronic submission of assignments, and the Course Materials Database (CMD), which was developed by the QUT Library to provide 


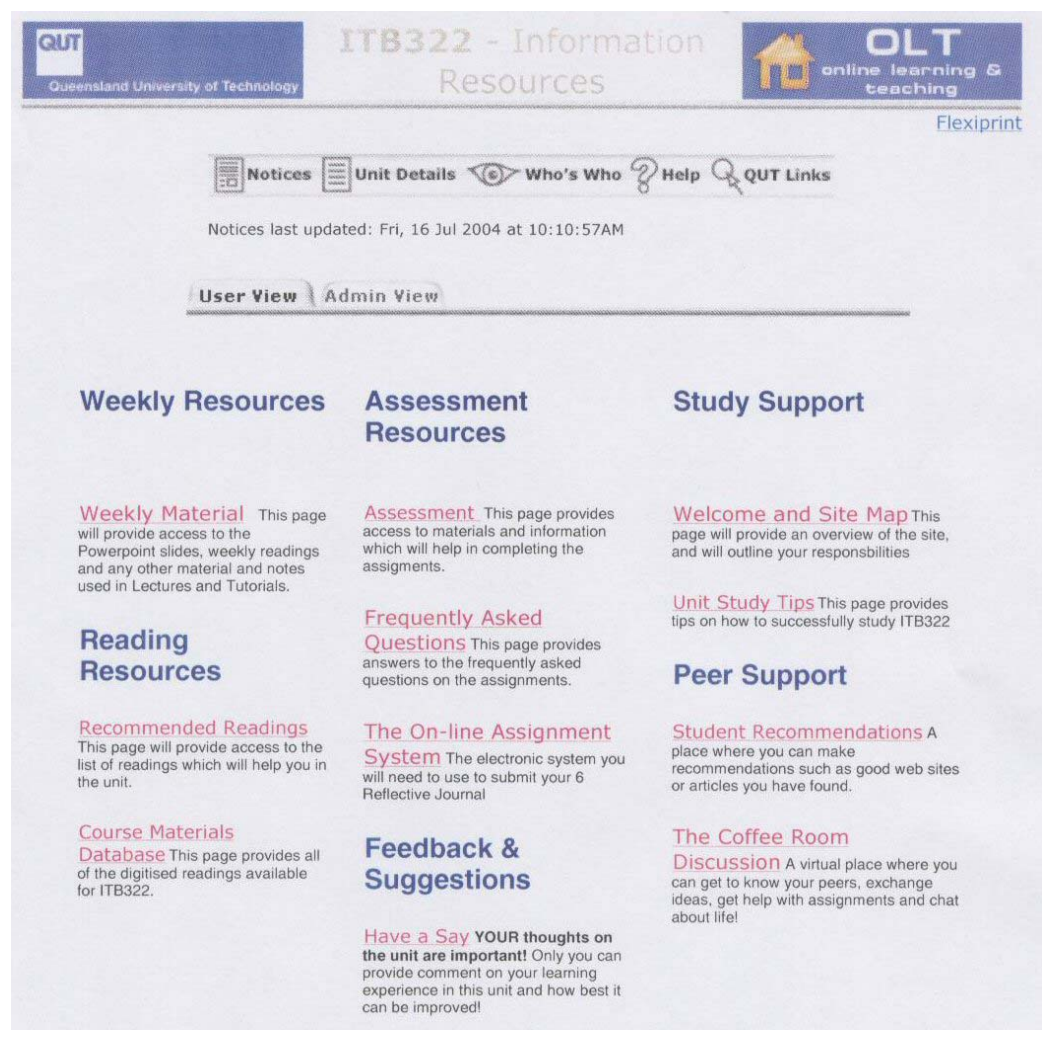

Figure 2: The ITB322 OLT Site

online full text access to unit readings. Whilst the CMD and the OAS are core online tools at QUT, it is the OLT site that will be the focus for the current study's exploration of e-learning.

\section{Students Perceptions of E-Learning in ITB322}

In order to identify and explore students' perceptions and experience of e-learning within ITB322 specifically, and at QUT generally, student feedback and comments were obtained via self administered questionnaires in Week 12 of the semester. Quantitative data was obtained by asking students to indicate if they agreed or disagreed with a series of statements about their experiences and preferences regarding the use of online learning tools on a 7 point Likert scale ( $1=$ Strongly Disagree and $7=$ Strongly Agree). A number of open questions were included to encourage students to respond freely about their experiences. Students were told that their comments would be completely anonymous and confidential and that their involvement in the survey would not impact upon their results in the unit.

Twenty-two out of the 52 students enrolled in the unit completed the questionnaire. Ages ranged between 17 and 50 with the majority of participants aged between 19 and 25.19 of the participants were full time students, 1 was part time and 2 were unknown. Over half of the participants were enrolled in a straight Bachelor of Information Technology $(n=14)$ degree with the remaining participants enrolled in an IT double degree (i.e. Bachelor of Business/Bachelor of Information Technology or Bachelor of Information Technology/Bachelor of Laws or Bachelor of Health Sciences/Bachelor of Information Technology. Only 2 of the participants had completed a unit or course delivered solely online (i.e. has no face-to-face contact).

The results from the survey suggest that the students view online learning favourably. Table 2 provides a summary of the results obtained. Student responses clearly indicate that students viewed favourably the use of e-learning within ITB322 specifically, and in higher education at 
Table 2. Summary of survey results $(n=22)$

\begin{tabular}{|l|c|}
\hline (1= Strongly Disagree, 4= Neutral, 7=Strongly Agree) & $\begin{array}{c}\text { Mean } \\
\text { Rating }\end{array}$ \\
\hline & 5.64 \\
\hline The OLT site in this unit is easy to use and understand & 5.68 \\
\hline The OLT site has increased flexibility in my studies within the unit & 6.00 \\
\hline The use of the OLT site has facilitated my studies within the unit & 4.59 \\
\hline The use of the OLT site has improved communications with the unit's teaching staff & 3.23 \\
\hline The use of the OLT site has improved communication with other students in the unit & 5.64 \\
\hline The use of the OLT site has helped me to understand the unit's content & 5.82 \\
\hline The use of the OLT site has improved the teaching and learning value of the unit & 5.82 \\
\hline I liked using the OLT site in this unit & 5.95 \\
\hline Overall I was satisfied with my experience of the OLT site in this unit & 6.86 \\
\hline All units should provide session materials (i.e. lecture notes \& tutorial activities) online & 7.00 \\
\hline All units should provided unit materials (i.e. unit outlines, assessment guides) online & 6.95 \\
\hline All units should provide online access to require reading materials & 6.23 \\
\hline All units should use a class email list & 6.77 \\
\hline All units should have an OLT site & 4.64 \\
\hline All units should provide a video of the lecture online & 5.5 \\
\hline All units should provide online class chat rooms & 6.14 \\
\hline All units should use an online notice board & 6.00 \\
\hline All units should provide a student discussion forum & 3.36 \\
\hline The content of this unit can be effectively taught online (i.e. no face-to-face classes) & 3.32 \\
\hline If this unit was taught solely online (i.e. no face-to-face) classes I would take it & \\
\hline
\end{tabular}

QUT generally. The overall average responses ranged from 3.32 to 7.00 (1-Strongly Disagree and $7=$ Strongly Agree). In discussing the use of the OLT site within the unit the highest average response were obtained in relation to the OLT's ability to "facilitate my studies in the unit" (6.00). Students also indicated that the OLT "increased flexibility in my studies" (5.68), "improved the teaching and learning value of the unit (5.82) and that overall they were "satisfied with my experience of the OLT in the unit" (5.95). In fact one student commented that the ITB322 online teaching site was "the best OLT [site] from any of my units so far". The lowest response obtained from students was in relation to the OLT's ability to "improving communication with the unit's teaching staff" (4.59) and finally the ability to "improve communication with other students in the unit" (3.23). The latter being a slightly negative result.

When asked to identify and discuss what features of the unit's OLT they liked the best the students identified the following: "the convenience and ease of access"; "the access to the weekly session materials"; "the access to assignment guides and help pages"; "the standardized and fun layout"; and "the frequency with which the site was updated". When asked to identify and discuss the features of the OLT site that they liked least the majority of responses were in relation to the functionality and layout of the site. For example several students commented that the site was too large requiring too much navigation to get to the desired information. As one student stated it "takes too many [mouse] clicks to get to where I want to go, frustrating at times when I'm in a hurry". Similarly comments were obtained in regards to the requirements to always enter usernames and passwords to enter the system (which is a QUT security measure) and the size of some of the site graphics being too large and causing a delay in viewing the site. 
Over half of the students $(\mathrm{n}=14)$ indicated that they accessed the unit's OLT site on a daily basis. When asked to indicate why they used the OLT site, the four main reasons identified were to access session materials ( $100 \%$ of respondents); access to unit reading materials ( $91 \%$ of respondents); access to unit materials (91\% of respondents), and to obtain assignment support such as sample assignments, assessment feedback and FAQ's (91\% of respondents). Whilst just over half of the respondents $(54.5 \%)$ indicated they used the site to receive communication from the unit teaching staff, only a small number of respondents (13.6\%) indicated they used the site to communicate with peers. No respondents used the site to provide feedback to the unit coordinator.

Further evidence on student use of the OLT can be obtained from the sites visitor logs, which indicated that 6133 visits during the semester were made to the site with the Weekly Materials page (3081 visits) and the Assessment page (1060 visits) receiving the highest number of visits. The visitors $\log$ records visits to the individual site pages by either students or staff during the 13 week semester. Whilst the Student Recommendations page and the Coffee Room Discussion received a reasonable number of students visits (159 and 109 respectively), only 1 student submitted a contribution to the recommendations page and only 2 students posted messages on the discussion room notice board.

In considering the information provided from the site visitors log it should be noted that whilst the logs provide an idea of "site traffic" it does not provide a detailed profile of this traffic. For instance the figures do not differentiate between students and staff visiting the site, nor do they indicate how many of the enrolled students visited the site (i.e. 1 student visiting twice a day or 50 students visiting twice in a semester).

Overall the students disagreed with the view that the unit's content could be effectively taught in only online mode (i.e. no face-to-face classes) (3.36). They also indicated that they would not have completed the unit if was only offered as an online unit (3.32). It should be noted that as these two questions were negatively worded the lower score represents a positive response. Several comments in support of the presence of face-to-face classes within the curriculum were offered by two of the students: "I think the use of the [OLT] is great, but there should never be no face to face contact"; "I think the OLT [is] fantastic in conjunction with real life teaching, nothing can replace actually talking to people".

When considering the use of the OLT generally at QUT, 100\% of the students agreed that all units at QUT "should provide unit materials online". Students also indicated that all units should have an OLT site (6.77) that provides access to session materials (6.86), reading materials (6.96), a student's discussion forum (6.00) and a class email list (6.23). However students had reservations about the quality of the OLT sites. One student commented that "when they are working these services are great". Students indicated that, in theory, online teaching tools such as the OLT are beneficial, however, in practice students identified two points which limited the full potential of online teaching tools being explored: inconsistent and poorly performing technology (i.e. servers crashing) and as one students described it "lazy lecturers not updating" the information on the site or who "can't use it properly". The lowest response obtained from students was a only a slight preference towards the idea that all units should provide a video of the lecture online (4.64) and a slightly higher preference towards each unit offering the provision of student chat rooms (5.5).

\section{The Next Step Forward - Developing a 'Radical Model' to e- Learning in ITB322}

The results of the project indicate that overall there has been a favourable response on the part of the students to e-learning within the unit, and within higher education at QUT. One significant observation that can be made based upon the current study is that technology should not be the 
sole focus of the learning environment. In short, this means that e-learning should be a part of a 'whole of learning' approach in which technology is not just an add on to traditional teaching, nor is it the central focus of teaching, but rather, it is one of many tools that is integrated into the curriculum to foster learning. The current project suggests that students appreciate and prefer a mix of e-learning and face-to-face classes. One comment received by a student at the end of the semester was representative of the many comments obtained when students were asked about what aspects of the unit were done well and should be continued: "class interaction in lectures, interaction between class members in both lectures and tutes".

It is interesting to note that even though the students indicated that they expect units they are enrolled in to provide online resources to facilitate communication between themselves, other students, and with the unit teaching staff, only one student enrolled in the unit used the online discussion forum and the student recommendations page. One point to consider here is that a constructivist learning approach guided the design and development of unit learning activities, so class sessions, be they lectures or tutorials, draw heavily on small group and in-class discussions. Throughout the semester students were openly encouraged to view themselves as part of a learning community in which "no one is excluded and in which learning is an enjoyable and rewarding thing to do". It is possible that the communication and social interaction offered via the online resource provided in the OLT simply could not compare in terms of the depth and richness of social interaction offered in the face-to-face classes. As Aristotle said "man is by nature a social animal".

ITB322 is not a static unit. It changes and evolves each semester in an effort to continually improve and refine the leaning environment. As such the observations drawn from the current research regarding student perceptions to the role of e-learning within the unit ITB322 were used to solve an issue in the unit development that had been noted in previous semesters.

From 2000 to 2002 Edwards conducted a study examining student experiences in learning how to conduct online searching whilst enrolled in the unit ITB322. The study by Edwards (Edwards \& Bruce, 2004) clearly showed that the ITB322 learning environment was successful in developing the information searching skills of students enrolled in the unit. However, the study also revealed that "there is a need to design the assessment to make the assignments work harder" (p. 154). Recent observation from the unit's teaching staff supported this conclusion. In particular, it was noted that whilst Assignment 1 (The Resource Guide) and Assignment 3 (The Reflective Learning Journal) were contributing successfully to student learning, Assignment 2 (The Information Consultant's Report) was not impacting upon student learning as significantly as it could. The second assignment was designed to challenge the students in their development of online searching skills and knowledge. In the assignment the student's were required to use the online searching process to meet a client's specific information need, and it was noted that whilst students could discuss the many elements of the online searching process, they had trouble in combining these elements together and applying them to the assignment. For example, students were able to select appropriate search tools, identify key concepts and synonyms but had difficulty in drawing these together to create search statements appropriate to each specific searching tool chosen.

The challenge for the unit's teaching staff was to identify how the current existing environment could be carefully re-constructed to bring about change (i.e. to make assignment 2 'work harder') without detracting from the elements in the environment that were working well. Guided by the findings the current study e-learning was identified as a possible answer to the problem on hand. A decision was made to push the current implementation of e-learning within the unit from the current standard/evolutionary model to a radical model (Roberts \& Jones, 2001). Grounded in the results of the Edwards study a new online resource to be embedded within the unit was developed - The Reflective Searching Skills (ROSS) Environment. 

Week 3: Introduction to Dialog \& Brushing up on Teamwork

Week 4: Introduction to

Internet Searching

Week 5: Introduction to

Print Resources \& The

Power of Information for

Business

Week 6: Assignment 1

Presentations

Week 7: Assignment 1

Clinic

Week $8-12$ Session

Materials

Introduction to the ROSS

environment

Reflective workspace

Ross Module 1 -

Understanding the

information need

Mosthe 1-Actarts -

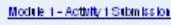

Modat 1- Actalty2

Modate 1-Actants

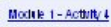

Ross Module 2 -

Planning an information

search

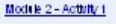

Hodte 2 - Actinte 2

Woclat 2-Acturty

Ross Module 3 .

Selecting the online

information resources

\section{Introduction to the ROSS environment}

\author{
ROSS = Reflective Online Searching Skills
}

ROSS is an online tool designed to help you improve your skills in online searching. There are 7 modules to be completed.

Module 1: Understanding the information need - will introduce you to process of obtaining information from a client so that you can successfully understand a clients information need.

Module 2: Preparing for the information search - will introduce you to the steps you should follow when preparing to conduct an online search.

Module 3: Selecting the online information resources - will introduce you to the process of selecting online information resources relevant to the information need.

Module 4: Designing and running the information search - will introduce you to the process of develop search strategies specific to the online resources you have selected.

Module 5: Reflecting on the information search - will introduce you to the process of reflecting on your search results and refining and running a revised search.

Module 6: Identifying high quality results - will introduce you to the process of selecting high quality results from the many results you will have obtained from you searches. You will also be introduced to the Alerts as a means of keeping up todate on the information needed.

Module 7: Critical reflection - will provide you the opportunity to critically reflect upon the new skills you have been developing

Each module builds upon the previous one. By working though the modules during class time you will develop your searching skills. Feel free however, to explore the Ross environment in your own time. To access the modules use the menu bar on the left hand side of the screen.

The Information Searching Process Model (see image) is used in ROSS. In

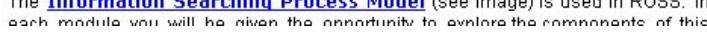

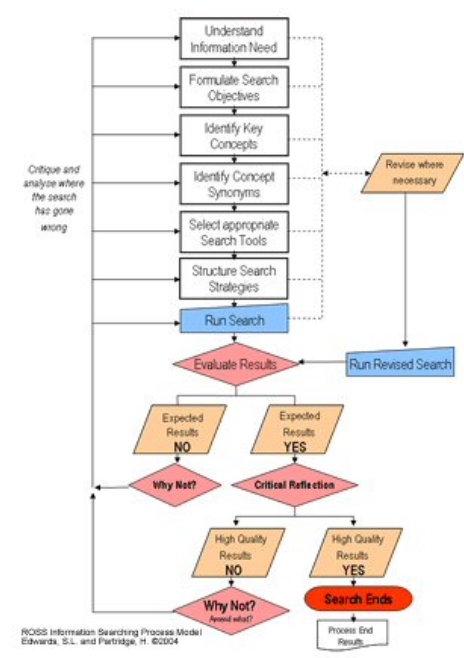

Figure 3: The ROSS Entry Screen

The entry screen of ROSS is provided in Figure 3. The environment was been incorporated into the unit's learning environment during Weeks 8 to 13. Each week during this period students attended a three hour computer laboratory based class. Using a role play approach ROSS requires the students to take on the role of an information consultant who has been approached by a client with a specific information need that must be met. The student is required to locate information to meet the client's need by selecting and searching online resources. ROSS consists of seven mod-

\section{Table 3: The five modules of ROSS}

Module 1: Understanding the information need - introduces the steps involved in successfully understanding a clients information need.

Module 2: Preparing for the information search - introduces the steps to follow when preparing to conduct an online search.

Module 3: Selecting the online information resources - introduces the process of selecting online information resources relevant to the information need.

Module 4: Designing and running the information search - introduces the process of developing search strategies specific to the online resources selected.

Module 5: Reflecting on the information search - introduces the process of reflecting on the search results and refining and running a revised search.

Module 6: Identifying high quality results - introduces the process of selecting high quality results from the many results obtained from searches.

Module 7: Critical reflection - provides the opportunity to critically reflect upon the new skills developed. 
ules. The modules are inter-related with subsequent modules building upon the former. A brief summary of the seven modules is provided in Table 3. A short video introduces the students to each module, explaining the purpose of the module and the activities to be completed. Each module is interactive requiring the students to answer questions, make observations and complete exercises. A Reflective Workspace is provided for the students. The Workspace can act as a 'sandpit site' where student can apply what they are doing within the ROSS modules to their own chosen assignment topic. Whilst the students will be completing the modules in class time they are also encouraged to use the ROSS environment as a self paced learning tool that they can access and use any time during the course of the unit.

ROSS was introduced as a pilot test into the unit in Semester 1 2004, with only 17 students enrolled in the unit. A detailed discussion of ROSS and its testing in the unit is provided in Partridge \& Edwards (2004). The pilot test revealed that while ROSS was an e-learning tool of merit, a revised version was needed, which should be based on the critical comments received by the students. The revised ROSS was pilot tested in the Semester 2 2004, with 40 students enrolled in the unit.

Figure 4 provides a schematic overview of the relationship between the many e-learning components (ie ROSS, OLT, OAS, CMD) in the new 'radical model' to e-learning.

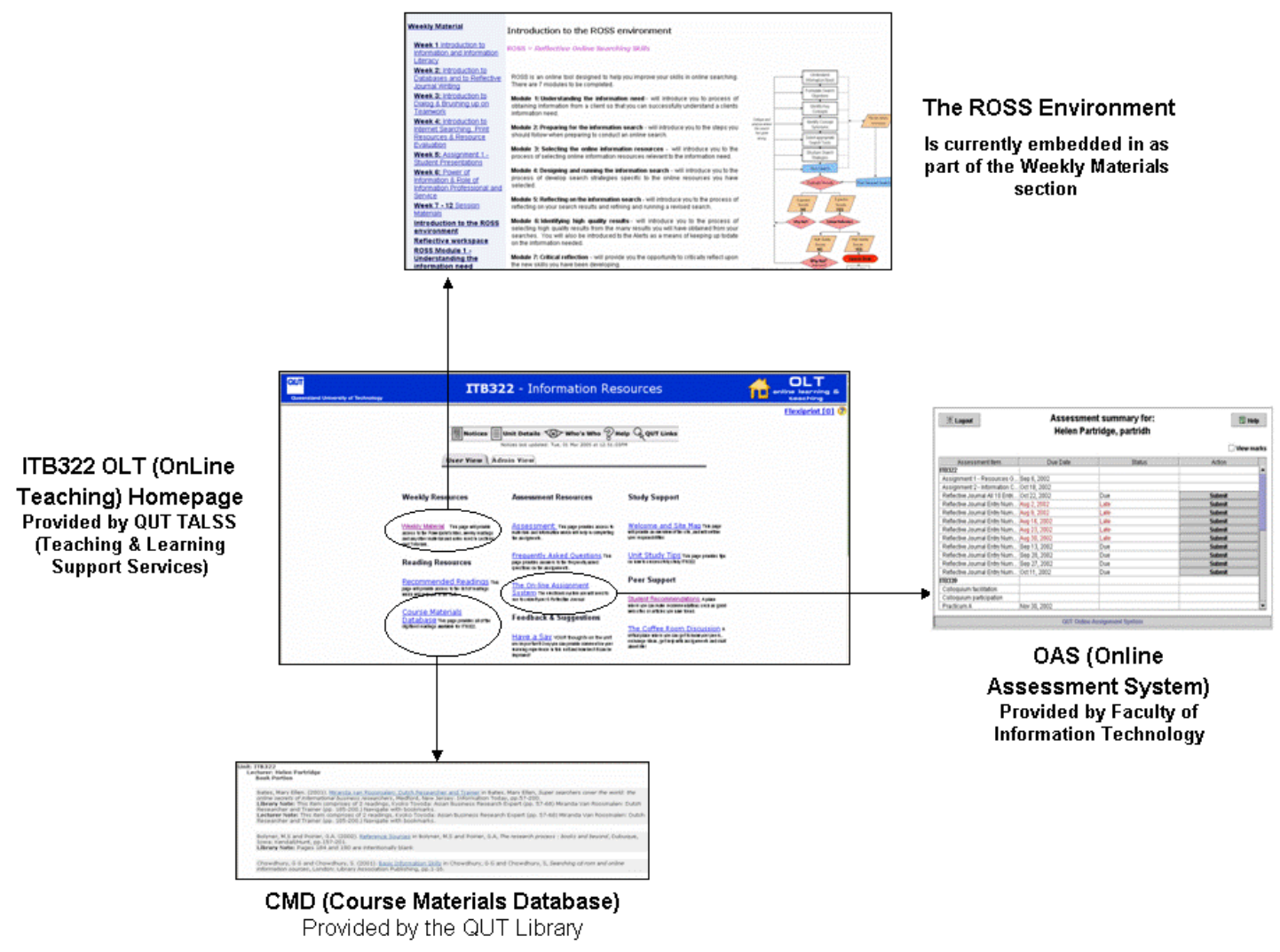

Figure 4: The relationship between the ITB322 e-learning components in the 'radical model'

During the semester students were encouraged to provide constructive comment and feedback on their experience of using ROSS. Student feedback was obtained via self administered questionnaires in Week 12 of the semester. Again quantitative data was obtained by asking students to 
indicate if they agreed or disagreed with a series of statements about their experiences and preferences regarding the use of online learning tools on a 7 point Likert scale.

Twenty-three out of the 40 students enrolled in the unit completed the questionnaire. Ages ranged between 21 and 65+ with the majority of participants aged between 19 and 25.18 of the participants were full time students, 3 were part time students and 2 students did not identify their enrollment type. Whilst there is not the space in the current paper to provide a full analysis of the survey findings the results suggest that the students have again viewed the experience of using ROSS favourably. Table 3 provides a summary of the results obtained. The overall average responses ranged from 4.40 to 5.22. The following student is representative of many received throughout the semester: "[ROSS was one of them most interesting tools to learn [with] during my time at university...it was very user-friendly and informative and thus quite enjoyable. The tool was closely related to the assessment...thus... [students] were rewarded for its completion".

Table 3: Summary of student survey results $(n=9)$

\begin{tabular}{|l|c|}
\hline (1= Strongly Disagree, 4= Neutral, 7= Strongly Agree) & Mean Rating \\
\hline ROSS is easy to use and understand & 5.22 \\
ROSS has increased flexibility in my studies within the unit & 4.70 \\
ROSS has facilitated my studies within the unit & 5.91 \\
ROSS has helped me to understand the unit's content & 5.00 \\
ROSS has improved the teaching and learning value of the unit & 5.00 \\
ROSS has helped me to successfully complete Assignment 2 & 4.40 \\
I liked using ROSS in this unit & 5.00 \\
Overall I was satisfied with my experience of ROSS in the unit & \\
\hline
\end{tabular}

From the teacher's perspective, ROSS provided a wonderful means of introducing new energy into the unit. However, it also posed challenges in how best to integrate the technology into the curriculum in a manner that balanced the virtues of self paced instruction alongside the benefits of maintaining a collaborative learning community in which peer discussion and small group work play central roles. This challenge was met by adopting a holistic approach to the unit's teaching and learning; holistic in that the whole is more than the sum of the parts in the learning environment. In particular a strategy adopted was that students should both learn by doing, by discussing, and by reflecting on the process with others. The social interaction of a learning community was therefore a vital ingredient in embedding the tool into the unit curriculum. The holistic approach required that ROSS not be viewed as the central tenet of the learning environment but simply as one of many tools or techniques (i.e. role playing activities, brainstorming sessions, small group discussions) that could be drawn upon during any class session to foster student learning. ROSS was carefully integrated into the existing curriculum so as to provide amply opportunity for student interaction and social engagement, and it is because of this perspective to the role of ROSS in the unit (and consequently e-learning generally), that the unit's teaching staff believes ROSS has been a factor that has lead to the overall online environment success.

\section{Research Limitations}

This research is limited in two significant ways: Firstly, the study does not provide any baseline data for comparison. For example, the inclusion of a control group of students undertaking the 
unit ITB322 without the presence e-learning aids, and, a comparison group of students experiencing e-learning as applied in another unit, would provide interesting comparative data that would allow a richer discussion. Secondly, the study is limited by the small number of participants. ITB322 is an elective unit, because of this enrolments vary considerable from semester to semester. In the current study $42 \%$ (22 out of 52) of the students enrolled in semester 22003 , and 53\% ( 9 out of 17) of the students enrolled in semester 12004 participated in the study. The current research project was an unfunded activity undertaken by the authors because of their genuine interest in learning more about the student experience and perception of the e-learning strategies being applied within the ITB322 curriculum. The lack of funding available significantly limited the design and implementation of the research (i.e. no extra teaching staff or lab resources were available). Despite the limitations outlined here the research presented in the current paper provides valuable, preliminary insight into the attitudes and expectations of students to e-learning with the Faculty of Information Technology at QUT. Further case studies exploring student reactions to e-learning will be added to the data pool as they arise.

\section{Conclusion}

In 2001 Zenger and Uehlein observed that in the recent "rush to e-learning the emphasis has been largely on the $e$ and not the learning (p. 60). If e-learning is to have a meaningful role in higher education in fostering quality student learning than it is important that universities firstly, examine how e-learning is being implemented within their institutions; and secondly, engage in an open dialogue with students to identify the attitudes and expectations of students regarding the role of e-learning within their higher education experience. The current paper has taken a small step in exploring these two points. Firstly, it has provided a detailed discussion on how e-learning is being applied within an undergraduate IT unit at QUT. Secondly, it has gathered preliminary data on the attitudes and expectations of IT students at QUT regarding the current and future role of e-learning. The results from the current study suggest that students view e-learning favorably. However, the results also support the recent observation made by the Australian Department of Education Science and Training (DEST) that "students....are still...demanding face-to-face access to teachers and educational experiences" and that "campus-based learning is likely to remain attractive on social grounds but can also be transformed by e-learning strategies" (p. 12). The current paper clearly shows that e-learning is successful when a holistic approach to teaching and learning is taken. Or as suggested by Poindexter (2003) "it is only when the whole environment is considered, and multiple tools used at appropriate times, that higher levels of sustained learning can be achieved" (pg. 30).

\section{References}

Alderman, B. \& Milne, T. (1999). Designing a web-based distance education course within a constructivist learning environment. HERDSA Annual International Conference. Melbourne, 12-15 July 1999.

Australian Department of Education Science and Training (2002). Education at the crossroads. A ministerial discussion paper. Retrieved, December $1^{\text {st }}, 2004$, from http://www.backingaustraliasfuture.gov.au/publications/crossroads/default.htm

Australian Universities Teaching Committee (2002). The centrality of learning. Higher Education Review, Australia. Retrieved, December $1^{\text {st }}, 2004$, from http://www.backingaustraliasfuture.gov.au/submissions/crossroads/pdf/10.pdf

Bell, M. Bush, D. Nicholson, P, O’Brien, D \& Tren, T. (2002). Universities online: A survey of online education and services in Australia. Occasional Paper Series, Commonwealth Department of Education, Science and Training. Retrieved, March $1^{\text {st }}, 2005$, from http://www.dest.gov.au/highered/occpaper/02a/02 a.pdf 
Edwards, S. L. \& Bruce, C. S. (2004). The assignment that triggered change: Assessment and the relational learning model for generic capabilities. Assessment and Evaluation in Higher Education, 29 (2), 141 157.

Heppell, S. (2002). The future of e-learning. Connected, 6. Retrieved, August $4^{\text {th }}, 2004$, from http://www.ltscotland.org.uk/connected/connected6/e-learning/futureelearning.asp

Hicks, S. (n.d). How to measure the success of your e-learning program. Career Journal Europe.com. Retrieved, December $1^{\text {st }}, 2004$, from http://www.careerjournaleurope.com/hrcenter/astd/features/20010321-hicks.html

Imel, S. (2002). E-learning: Trends and issues alert. ERIC Clearinghouse on Adult, Career, and Vocational Education. Report Number 40.

Keller, C, \& Lars, C. (2002). Students' perceptions of e-learning in university education. Journal of Educational Media, 27 (1/2), 55-67.

Luca, J. Oliver, R., Omari, A., \& Dunbar, Al. (2001). Designing an on-line learning environment to support the development of generic skills: A case study. In N. Smythe (Ed.), E-Xplore 2001: A face-to-face odyssey. Proceedings from the Apple University Consortium Conference, September 23-26 2001.Townsville Australia. Retrieved, November $11^{\text {th }}$, 2004, from http://auc.uow.edu.au/conf/conf01/downloads/AUC2001_Luca.pdf

Oliver, R. (1999). Exploring strategies for online teaching and learning. Distance Education, 20 (2), 240.

Parker, M. (2003). Technology-enhanced e-learning: Perceptions of first year information systems students at the Cape Technikon. Proceedings Of The 2003 Annual Research Conference of the South African Institute of Computer Scientists and Information Technologists on Enablement through Technology (SAICSIT) 2003. Retrieved, December $1^{\text {st }}, 2004$, from http://delivery.acm.org/10.1145/960000/954049/p316parker.pdf?key $1=954049 \&$ key $2=0750103011 \&$ coll $=$ GUIDE $\& d l=$ GUIDE $\&$ CFID $=33813107 \& C F T O K$ $\underline{\mathrm{EN}=86548055}$

Partridge, H., \& Edwards, S. L. (2004). The rippling pond: Ruminations and other musings on the development and use of an online learning environment in the Faculty of Information Technology. Exploring integrated learning environments. OLT 2004 Conference Proceedings. Online Learning and Teaching Conference, Brisbane, 3 November 2004. Brisbane, Australia.

Poindexter, S. (2003). The case for holistic learning. Change, 25 (1), 24-30.

QUT. (1999). Report 1 (February 1999) on Central Initiative Projects 1999 - On Line Teaching \& Learning Support. Retrieved November $11^{\text {th }}$, 2004, from, https://olt.qut.edu.au/int/colt/sec/index.cfm? fa=displayPage\&rNum $=7480$

QUT. (2003). QUT Blueprint. Retrieved November $11^{\text {th }}$, 2004, from https://www.qut.edu.au/frp/perf/qut_blueprint.pdf

Roberts, T. S. \& Jones, D. T. (2000). Four models of on-line teaching. Proceedings of the Technological Education and National Development Conference. Crossroads of the New Millennium. April 8-10, 2000, Abu Dhabia, United Arab Emirates.

Small, H. \& Lohrasbi, A. (2003). MBA student perspective on online degrees and courses: an empirical analysis. International Journal of E-Learning, April-June, 5-14.

Wang, W. (2004). How university students view online study: A PCP perspective. Campus wide Information Systems, 21 (3), 108-117.

Zenger, J. \& Uehlein, C. (2001). Why blended will win. $T \& D$, 55(8), 54-60. 


\section{Acknowledgements}

The authors would like to acknowledge the contributions from the staff at the Teaching and Learning Support Services (TALSS) at QUT. In addition, the authors thank the research assistant, Lynn McAllister, the student observer, Anne Griffiths, and the ITB322 students for their enthusiasm and willingness to take part in the project.

\section{Biographies}

Helen Partridge is a Lecturer in the Faculty of Information Technology. She teaches in the areas of information resources, reference and information services and in-

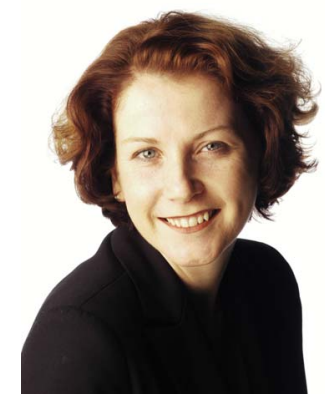
formation literacy. Helen has received several teaching and learning awards including a 2004 QUT Vice Chancellors Distinguished Teaching Award, the 2004 Faculty of Information Technology Dean's Award for Teaching Excellence (with Gillian Hallam for team teaching), the 2004 OLT Compassionate Pioneer Award and the 2003 Faculty of Information Technology Award for Teaching Scholarship (with Gillian Hallam for a jointly written paper). Prior to joining QUT, Helen worked as a library and information professional in both public and special libraries. Helen is a member of the Higher Education Research and Development Society of Australasia (HERDSA) and the Association for Library and Information Science Education (ALISE).

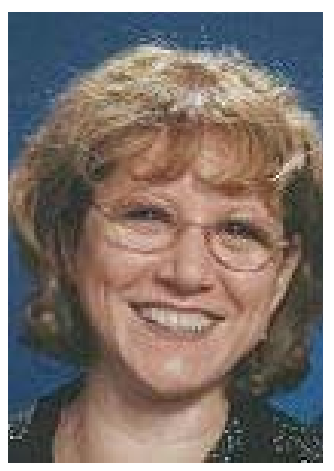

Sylvia Lauretta Edwards was appointed as a QUT Teaching Fellow, July 2002 to Jan 2005, in the inaugural round of Teaching Fellowship appointments. She is also a Lecturer in the Faculty of Information Technology at QUT. Sylvia has received several teaching awards including the 2004 QUT Vice-Chancellor's Distinguished Teaching Award, the 1999 QUT Outstanding Academic Achievement Award (Teaching), the 2004 Faculty of Information Technology Teaching Scholarship Award, the 2000 Faculty of Information Technology Outstanding Performance Award, and a 2004 QUT OLT Compassionate Pioneer Award. Before joining QUT in 1995 Sylvia worked as an information broker and librarian in the business and academic library sectors. Sylvia is a member of the Higher Education Research and Development Society of Australasia (HERDSA) and a member of the Australian Computer Society (ACS).

In 2004 Sylvia and Helen received a QUT Teaching and Learning Development Grant to refine and develop the ROSS environment for use in other faculties in QUT. 